\title{
Avaliação de ambiente virtual de aprendizagem
}

\author{
em cursos de educação física
}

Evaluation of virtual learning environment

in physical education courses

\section{Evaluación del entorno de aprendizaje virtual \\ en cursos de educación física}

\author{
Claudio Severino Delunardo \\ Centro Universitário de Volta Redonda (UniFOA), Volta Redonda/RJ - Brasil \\ Ivanete Da Rosa Silva de Oliveira \\ Centro Universitário de Volta Redonda (UniFOA), Volta Redonda/RJ - Brasil \\ Silvio Henrique Vilela \\ Centro Universitário de Volta Redonda (UniFOA), Volta Redonda/RJ - Brasil
}

\begin{abstract}
Resumo
Mesmo antes das adversidades causadas pela pandemia da Covid-19, o Ambiente Virtual de Aprendizagem (AVA) já era visto como uma possibilidade de recurso educacional diante do incremento de procedimentos pedagógicos e no aperfeiçoamento da interação entre docentes e alunos. Assim, notou-se, por parte das instituições, a necessidade de apresentar soluções inovadoras que atendessem às demandas de ordem pedagógica, por meio de mecanismos que estivessem em consonância com os anseios de um público cada vez mais "digital". O objetivo do estudo é avaliar o desenvolvimento de atividades pedagógicas no AVA, em cursos de educação física. Para isso, a metodologia empregada está vinculada a uma pesquisa quantitativa descritiva, com o intuito de desenvolver condições para realizar avaliações críticas. A partir dos resultados obtidos, observou-se que o desenvolvimento das atividades no AVA vem alcançando êxito quanto ao processo de formação acadêmica, consolidando, portanto, mais um cenário de aprendizagem para a educação física.
\end{abstract}

Palavras-chave: Educação, Educação física, Tecnologia, Ambiente Virtual de Aprendizagem

\begin{abstract}
Even before the adversities caused by the Covid-19 pandemic, the Virtual Learning Environment was already seen as a possibility of an educational resource due to the increase in pedagogical procedures and in the improvement of the between teachers and students. Thus, there was a need from part of the institutions to present innovative solutions that would meet pedagogical order demands through mechanisms that were in line with the desires of an increasingly "digital" audience. The objective of the study is to evaluate the development of pedagogical activities in VLE in physical education degrees. The methodology used is linked to descriptive quantitative research to develop conditions to conduct critical assessments. The results showed that the development of
\end{abstract}


activities in VLE achieved success in terms of academic training process, consolidating, therefore, another learning scenario for physical education.

Keywords: Education, Physical education, Technology, Virtual Learning Environment.

\section{Resumen}

Incluso antes de las adversidades provocadas por la pandemia del Covid-19, el Ambiente Virtual de Aprendizaje (AVA) ya se vislumbraba como una posibilidad de recurso educativo ante el aumento de los procedimientos pedagógicos y en la mejora de la interacción entre docentes y alumnos. Así, existía la necesidad por parte de las instituciones de presentar soluciones innovadoras que respondieran a las exigencias del orden pedagógico a través de mecanismos acordes con los deseos de una audiencia cada vez más "digital". El objetivo del estudio es evaluar el desarrollo de las actividades pedagógicas en los cursos AVA en cursos de educación física. Para ello, la metodología empleada se vincula a una investigación cuantitativa descriptiva con el fin de desarrollar condiciones para realizar valoraciones críticas. A partir de los resultados obtenidos, se observó que el desarrollo de las actividades en el AVA han ido logrando éxitos en cuanto al proceso de formación académica, consolidando, por tanto, otro escenario de aprendizaje para la educación física.

Palabras clave: Educación, Educación Física, Tecnología, Ambiente Virtual de aprendizaje

\section{Introdução}

A pandemia da Covid-19, causada pelo SARS-CoV2, trouxe inúmeras adversidades aos mais diversos setores da sociedade. Na educação, com o intuito de diminuir a propagação no novo coronavírus, inúmeras instituições educacionais, em todo o mundo, da educação infantil ao ensino superior, promoveram o cancelamento das aulas presenciais como medida de distanciamento social. Tal medida acarretou em uma transformação no processo educacional, fazendo com que as Tecnologias de Informação e Comunicação (TIC) passassem a representar um papel essencial para o desenvolvimento de atividades pedagógicas, além da sua representatividade quanto à relação discente-docente-instituição.

Nesse contexto, as instituições de ensino superior perceberam a necessidade, em caráter imediato, de enfrentar os desafios impostos pela pandemia. Esse enfrentamento consistiu em apresentar soluções práticas e inovadoras, que atendessem às demandas de ordem pedagógica, por intermédio de mecanismos dinâmicos, atrativos e que estivessem em consonância com os anseios de um público cada vez mais "digital". Além disso, estava em pauta 
também a necessidade de capacitar técnica e pedagogicamente os docentes para lidarem com aquela que, para muitos, representava uma nova modalidade de ensino e aprendizagem.

Para que tal capacitação se torne exitosa, ressalta-se a importância de que sejam considerados determinados fatores, entre eles, a atitude - positiva ou não - dos docentes em relação às TIC, o treinamento quanto à sua utilização nas atividades acadêmicas e a motivação para o envolvimento com um processo de inovação (BOLÍVAR, 2012). Sobre isso, Wardenski e colaboradores (2018) acrescentam que os docentes com maior experiência com recursos tecnológicos evidentemente apresentam maior segurança para os utilizar em suas práticas pedagógicas, além de demonstrarem disposição para associar as tecnologias a novas propostas educativas.

Mesmo antes do cenário estabelecido pela pandemia, o ambiente virtual de aprendizagem (AVA) já era percebido como uma possibilidade de recurso educacional, diante da disseminação dos conteúdos propostos, do incremento de procedimentos pedagógicos e no aperfeiçoamento da interação entre docentes e alunos. Entretanto, faz-se necessária a compreensão do AVA, para que se possa estabelecer a sua utilização da maneira mais adequada.

Nesse sentido, a avaliação desses ambientes a partir da opinião dos discentes que dele fazem uso torna-se relevante para que procedimentos associados ao seu emprego possam ser discutidos, analisados e aperfeiçoados (ANJOS et al., 2016). Ressalta-se que a análise do AVA e das TIC, de acordo com Laguardia e colaboradores (2007), não deve se restringir unicamente aos seus aspectos tecnológicos, mas deve contemplar a interação com os seus usuários, o que, de fato, determina de que maneira ocorre o emprego das tecnologias no processo educacional. Para isso, uma avaliação referente ao AVA deve estar amparada nas questões levantadas pelos alunos que o utilizam, bem como na articulação das metodologias utilizadas pelos docentes, o que resultará em informações imprescindíveis para futuras tomadas de decisão.

Para Aguiar e Cassiani (2007), a avaliação no cenário educacional deve considerar tanto os aspectos quantitativos como os qualitativos, reconhecendo e analisando dados necessários para o diagnóstico das dificuldades e dos progressos em determinado processo, sempre com o intuito de promover a integração entre o produto educacional e os alunos, principais sujeitos do 
referido processo. Como resultado, a avaliação poderá oferecer contributos para a construção de saberes e o desenvolvimento dos alunos.

Essa avaliação, no entendimento de Mozzaquatro e Medina (2008), pode estabelecer como pontos de partida para a sua aplicação a estrutura na qual a aprendizagem ocorre, os procedimentos pelos quais os alunos são apoiados para o desenvolvimento das atividades e os resultados obtidos por eles em relação aos objetivos propostos.

Assim, o objetivo do presente estudo foi avaliar o Ambiente Virtual de Aprendizagem em cursos de educação física - bacharelado e licenciatura, na cidade de Volta Redonda, estado do Rio de Janeiro. A partir dos resultados obtidos, espera-se contribuir com informações a respeito de práticas educacionais amparadas na utilização de ferramentas tecnológicas e Ambientes Virtuais de Aprendizagem. Observa-se que o estudo se justifica pela elaboração de um aporte teórico que possa representar um contributo para a reflexão, por parte de professores e alunos, a respeito do processo de ensino e de aprendizagem em cursos de educação física.

\section{Enquadramento teórico}

\subsection{A integração das TIC no ensino}

Considera-se TIC todos os procedimentos e equipamentos empregados em um determinado processo de transmissão de informações, ou seja, todos as alternativas oferecidas pela tecnologia, que vão desde a simples utilização de aparelhos smartphones até o compartilhamento on-line de dados e informações diversas (REPETTO et al., 2019). Os mesmos autores se referem ainda às TIC como:

o conjunto de avanços tecnológicos desenvolvidos para gerenciar informações e enviá-las de um lugar para outro, onde são desenvolvidos processos de armazenamento, recuperação e comunicação de informações, trabalhando de forma interativa e interconectada em torno de três meios básicos: computação, microeletrônica e telecomunicações. (p. 38)

Nessa perspectiva, Correia e Santos (2013) colaboram com a observação de que as TIC possibilitaram a todos os seus usuários tanto a captação, como a transmissão de informações de forma mais eficaz e articulada, por intermédio da digitalização e da comunicação por meio de redes. Essa agilidade oportunizou 
uma rápida transferência de elementos em forma de texto, imagens, estáticas, sons ou vídeos.

É possível afirmar que as TIC são formadas por três áreas de aplicação que atuam de forma interdependentes, a saber, o computador, a comunicação e o controle. Ramos (2008), ao apresentar o significado de cada uma das áreas, comenta que o computador é o responsável pelos cálculos e as operações lógicas, realizados com reconhecida fiabilidade e celeridade. Sobre a comunicação, o referido autor a considera essencial à condição humana, para que haja entre os indivíduos o compartilhamento das mais variadas informações. Por fim, menciona-se o controle, que consiste nos mecanismos e nos equipamentos necessários para a interação entre os sujeitos que deles fazem uso.

As TIC podem ser reconhecidas pela sua relevância para o desenvolvimento das sociedades, principalmente, a respeito das áreas da produção científica, da organização social, do desenvolvimento econômico, dos campos da produção humana e da construção do conhecimento. Tais relações estabelecidas entre as TIC e a sociedade possibilitaram a desconstrução da poderosa representatividade que a humanidade atribuiu às tecnologias, assim como a compreensão mais exata dos seus limites e/ou das suas reais possibilidades (PINO, 2008). Tais expectativas na área da construção do conhecimento se concretizam, segundo Aguiar e Cassiani (2007), diante da aplicação dos conhecimentos de informática para o emprego adequado das ferramentas tecnológicas disponíveis,

Considerando que não é apenas o uso da informática, mas a utilização dos meios disponíveis dos livros aos softwares, desde que estejam em consonância com a proposta educativa no processo pedagógico, fundamentado em novas metodologias de ensino colaborativas e interdisciplinares. (AGUIAR; CASSIANO, 2007, p. 2)

Em se tratando de ferramentas educacionais associadas às TIC, os Ambientes Virtuais de Aprendizagem (AVA) são compreendidos como um campo potencial de embasamento ao processo de ensino e de aprendizagem, em qualquer nível acadêmico. No entanto, percebe-se a necessidade de que o AVA seja analisado de maneira criteriosa, para que o seu emprego possa estar em consonância com as abordagens pedagógicas apresentadas pelas instituições e docentes (SALVADOR et al., 2017). 
A considerar as exigências em relação ao desenvolvimento e à aplicação de estratégias educacionais inovadoras e eficazes, percebe-se que as TIC representam um potencial contributo para uma construção ativa do conhecimento por parte dos alunos, em dissonância com a mera transmissão de informações e a fragmentação de conteúdos (WARDENSKI et al., 2018; REPETTO et al., 2019).

\subsection{O Ambiente Virtual de Aprendizagem (AVA)}

Diante do cenário compreendido como o "novo normal", no qual novos hábitos foram associados ao cotidiano a partir das medidas necessárias para conter a pandemia, considera-se imprescindível que as práticas pedagógicas sejam integradas à sociedade do conhecimento, sendo o AVA um espaço no qual é possível, por intermédio da mediação das TIC, o desenvolvimento de estratégias educacionais (MOZZAQUATRO; MEDINA, 2008). Nesse caminho, Prado e colaboradores (2011) apontam que a utilização do AVA para o desenvolvimento de atividades acadêmicas possibilita aos alunos a construção do seu próprio conhecimento amparado pelas providenciais intervenções docentes, tornando-o, assim, mais prazeroso e significativo. Também, Behar e Leite (2006) o definem como um espaço na Internet que tem como essência o processo de ensino e aprendizagem, formado pelos sujeitos e suas maneiras de comunicação, estabelecidas por intermédio de uma plataforma de software.

O AVA, segundo Aguiar e Cassiani (2007), foi apresentado como um ambiente mediador que viesse a auxiliar o ensino presencial a partir da utilização das TIC para aquisição de múltiplas competências. Trata-se de formato mais flexível de aprendizagem, baseado na autonomia e também na liberdade intelectual dos sujeitos. Além disso, na perspectiva de Laguardia e colaboradores (2007), o AVA apresenta certa adequação à realidade daquele aluno que, mesmo inserido no mercado de trabalho, consegue contemplar suas necessidades de formação acadêmica e capacitação sem a perda de vínculos laborais. Os mesmos autores observam ainda que essa condição deve estar vinculada a uma ampliação da acessibilidade por parte do aluno, além da flexibilização pelas instituições educacionais e das estratégias pedagógicas empregadas pelos docentes adequadas ao ensino em ambiente remoto. 
O AVA, em consonância com o emprego de outros recursos tecnológicos, possibilita, por parte dos alunos, uma aprendizagem em caráter mais reflexivo, interativo e colaborativo, atribuído ao docente o cumprimento do papel de colaborador em todo o processo. Ele motiva os alunos, transmitindo informações, esclarecendo dúvidas e identificando problemas que porventura estejam dificultando o desenvolvimento das ações pedagógicas. Observa-se também que a utilização do AVA com um recurso de aprendizagem oferece variados benefícios, entre eles, a integração com outros recursos tecnológicos e o rápido acesso para informação e comunicação (AGUIAR; CASSIANI, 2007; PRADO et al., 2012; AVELINO et al., 2017).

Ainda em relação ao AVA, observa-se também a possibilidade da utilização de ferramentas de comunicação como, por exemplo, chats e fóruns, além do armazenamento e disponibilização de materiais didáticos vinculados aos conteúdos desenvolvidos. Tais ferramentas viabilizam um aprendizado que permite aos alunos uma flexibilização em relação ao tempo e ao espaço (SALVADOR et al., 2017).

Diante do que se apresenta em relação ao emprego do AVA para o desenvolvimento de um processo didático, Aguiar e Cassiani (2007) apontam que o limite de suas possibilidades consiste em saber ou não saber utilizar os seus recursos. O referido caminho, de acordo com os mesmos autores, significa representar um paradigma para a educação, no qual a utilização de recursos tecnológicos e as suas potencialidades possibilitam um melhor desenvolvimento das ações pedagógicas. Esse paradigma, para Repetto e colaboradores (2019), significa, como já mencionado anteriormente, a compreensão a respeito da diminuição da distância que separa os modelos educacionais considerados tradicionais de um formato de ensino diferenciado, o que resultará na substituição da simples educação baseada na recepção de informações por metodologias ativas de ensino.

\section{Metodologia}

O caminho metodológico percorrido para o desenvolvimento do presente estudo está vinculado a uma pesquisa quantitativa descritiva, com o intuito de desenvolver condições para realizar avaliações críticas. 
A pesquisa consistiu em avaliar o Ambiente Virtual de Aprendizagem (AVA) empregado para o desenvolvimento das atividades acadêmicas por parte alunos dos cursos de educação física - bacharelado e licenciatura do Centro Universitário de Volta Redonda - UniFOA, onde foi aplicado um questionário como instrumento de coleta de dados.

Para o desenvolvimento da pesquisa, foram obedecidas as seguintes fases: construção do referencial teórico, elaboração do questionário de avaliação, aplicação do questionário, análise quantiqualitativa dos resultados obtidos, discussão dos resultados obtidos e elaboração das conclusões.

Faz-se importante a observação de que os sujeitos participantes da pesquisa somente o fizeram a partir do cumprimento de todos os procedimentos éticos para a realização do estudo, que foi submetido ao Comitê de Pesquisas em Seres Humanos do Centro Universitário de Volta Redonda - UniFOA, sob o Parecer Consubstanciado n‥ 4.433.601 e Certificado de Apresentação para Apreciação Ética no. 39703320.4.0000.5237

\subsection{Participantes}

Os sujeitos participantes da presente pesquisa foram alunos matriculados nos cursos de educação física - bacharelado e licenciatura do Centro Universitário de Volta Redonda - UniFOA, sendo o número de entrevistados de 180 ( $n=180$ ). No que se refere aos cursos dos participantes, 151 (cinco) são matriculados no curso de bacharelado e 29 (vinte e nove) no curso de licenciatura (Gráfico 1).

Os critérios de inclusão para a participação da pesquisa foram: alunos regularmente matriculados nos cursos de educação física do Centro Universitário de Volta Redonda - UniFOA e que estivessem utilizando regularmente o AVA para cumprimento das suas atividades acadêmicas. Os critérios de exclusão se referem a alunos que, por alguma razão, não estavam acompanhando as atividades acadêmicas realizadas em ambiente remoto. 
Gráfico 1 - Sujeitos participantes da pesquisa

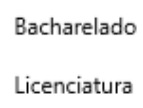

$$
\begin{aligned}
& 151 \\
& 29
\end{aligned}
$$

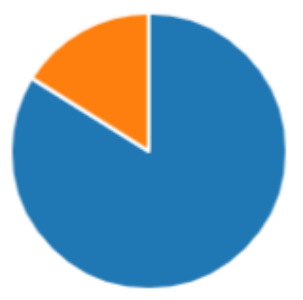

Fonte: Os autores

\subsection{Instrumento de coleta de dados}

Para a coleta de dados, utilizou-se um questionário, contendo questões fechadas e abertas, com o objetivo de expor as opiniões dos participantes acerca do objeto de estudo. Observa-se que o questionário utilizado foi desenvolvido no Microsoft Forms, escolhido pela facilidade de acesso e manipulação por parte dos usuários, além de sua maior disponibilidade, pois ele permanece disponível pelo tempo necessário. Para a construção do referido instrumento, utilizaram-se categorias empíricas estabelecidas a partir do referencial teórico associado ao presente estudo. Assim sendo, as categorias organizadas foram:

- Acesso

- $\quad$ Estrutura e design

- Práticas pedagógicas

- Avaliação

Note-se que, para a concepção do questionário, foi empregada uma escala Likert de cinco pontos, que mediu o nível de concordância ou discordância dos sujeitos participantes da pesquisa. Assim, as opções de resposta foram: Muito Boa, Boa, Regular, Ruim e Muito Ruim.

\subsection{Método de coleta de dados}

A respeito do emprego de questionários para a avaliação de AVAs, Mozzaquatro e Medina (2008) entendem que esse procedimento apresenta vantagens consideráveis, por exemplo, a celeridade na coleta dos dados, o baixo custo e as altas taxas de retorno.

O questionário foi aplicado em sistema on-line, no período de duas semanas, e o tempo de duração para o seu preenchimento por parte dos sujeitos participantes foi, em média, de nove minutos, aproximadamente. 


\section{Resultados e discussão}

Os dados referenciados como dificuldades apresentadas pelos alunos participantes da pesquisa são apresentados no Gráfico 2.

Notou-se que um número significativo de inquiridos (147), que representa $81,6 \%$ da amostra, considera satisfatória a qualidade do seu acesso ao AVA. Em consonância com a perspectiva de Repetto e colaboradores (2019), esse considerável percentual de alunos satisfeitos com a possibilidade de acessar um ambiente virtual sem dificuldades pode estar amparado no fato de que, atualmente, o sistema de telefonia móvel e a crescente utilização de aparelhos smartphones representam uma realidade presente na sociedade. Para os referidos autores, cada vez mais, os indivíduos compreendem os equipamentos tecnológicos como objetos essenciais para receber, armazenar, interpretar e administrar uma grande quantidade de informações.

De acordo com as informações obtidas e em conformidade com o estudo promovido por Aguiar e Cassiani (2007), observa-se que, mesmo que em baixa incidência, ainda há a necessidade de melhoria nas condições de acesso à Internet por parte dos alunos, não apenas para acompanhar as atividades acadêmicas realizadas no AVA, mas também para a obtenção de informações complementares para a construção de saberes. Ressalta-se que os dados obtidos em relação à qualidade do acesso ao AVA corroboram os resultados alcançados no estudo promovido por Santos e colaboradores (2017), mesmo que neste trabalho não tenha havido grande disparidade entre as respostas oferecidas pelos sujeitos participantes.

Gráfico 2 - Avaliação da qualidade do acesso ao AVA para o acompanhamento das atividades acadêmicas.

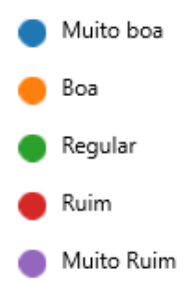

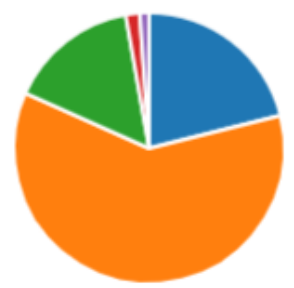

Fonte: Os autores 
O Gráfico 3 apresenta a opinião dos alunos a respeito da qualidade do acesso ao material de apoio disponibilizado pelos docentes para 0 acompanhamento das atividades acadêmicas realizadas no AVA. De acordo com as informações colhidas, 148 alunos $(81,6 \%)$ se consideram satisfeitos com esse aspecto e $32(17,7 \%)$ o avaliam apenas como regular. Não houve posicionamento negativo quanto a esse fator por parte de nenhum sujeito participante da pesquisa, o que nos remete à observação de que a qualidade de acesso ao AVA está combinada com a constante preocupação por parte dos docentes em assegurar aos alunos a obtenção dos materiais necessários para o êxito do processo de ensino e aprendizagem.

Ao ser questionada a qualidade do acesso ao material disponibilizado aos alunos, foi possível identificar uma alta aceitação por parte dos participantes da pesquisa, o que reforça, de acordo com o estudo realizado por Repetto e colaboradores (2019), o conceito de que as atividades acadêmicas realizadas em AVA, diante não apenas da flexibilidade do intercâmbio entre o docente e o aluno, mas também do acesso às informações disponibilizadas fora do horário de aula, possibilitam maior reflexão acerca dos conteúdos discutidos.

Gráfico 3 - Avaliação da qualidade do acesso ao material de apoio disponibilizado pelos docentes para o acompanhamento das atividades acadêmicas.

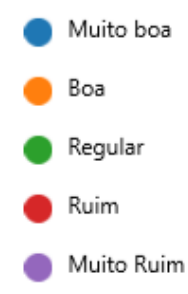

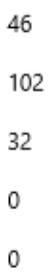

Fonte: Os autores

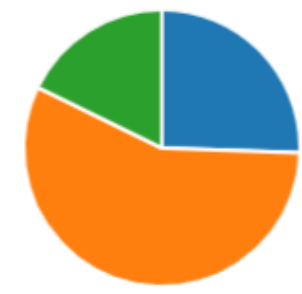

No que tange ao download de arquivos disponibilizados no AVA pelos docentes, 145 participantes $(81,6 \%)$ não tiveram problemas em relação a esse processo, conforme dados apresentados no Gráfico 4. Todavia, foi verificado, como sugestão por parte dos alunos, que os docentes tivessem a atenção para disponibilizar arquivos que não fossem pesados, considerando que muitos não dispõem de um sinal de Internet com qualidade suficiente para a execução de downloads mais demorados. 
Gráfico 4 - Capacidade em fazer o download do material de apoio disponibilizado no AVA pelos docentes.

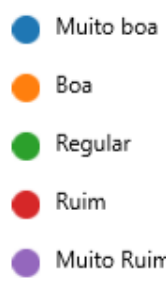
52
93
33
2
0

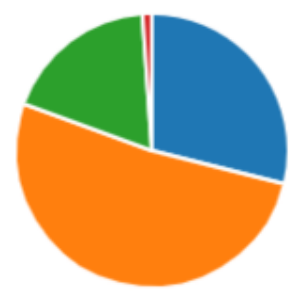

Fonte: Os autores

A respeito das possíveis dificuldades encontradas pelos sujeitos participantes da pesquisa, notou-se que 86 alunos $(47,7 \%)$ consideraram que não há dificuldades para o acompanhamento das atividades acadêmicas no ambiente virtual, conforme dados indicados no Gráfico 5. Todavia, como pode ser notado no referido gráfico, percebeu-se que a utilização das TIC como recurso educacional ainda oferece obstáculos para os alunos, por exemplo, a falta de tempo para acompanhar as aulas, as dificuldades ocasionais para o acesso à Internet e até mesmo a falta de habilidade para utilizar as ferramentas disponíveis. Esses fatores representam 45,5\% das observações realizadas pelos inquiridos. Além disso, os ocasionais problemas de saúde por parte dos alunos, a falta de qualidade dos equipamentos e a desmotivação causada por fatores externos também foram apontadas como adversidades que implicam em dificuldades para acessar o AVA.

Gráfico 5 - Dificuldades encontradas para o acesso ao AVA.
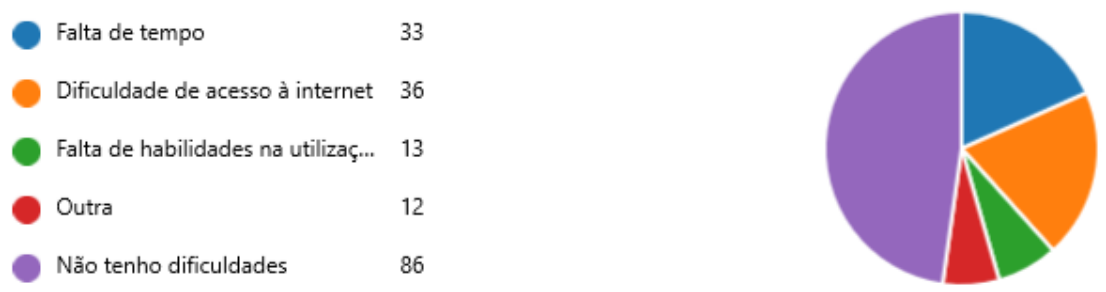

Fonte: Os autores

As alterações socioeconômicas e culturais causadas não somente pela pandemia da Covid - 19, mas também pelo reconhecido desenvolvimento das TIC, ao mesmo tempo em que elas se consolidam cada vez mais na rotina dos indivíduos, são apontadas há algum tempo por Laguardia e colaboradores 
(2007), como agentes de transformação dos sistemas de ensino e das modalidades educacionais.

Isso posto, mesmo a considerar a mencionada transformação, cada vez mais solidificada no ambiente educacional, nota-se que ainda são identificados alguns transtornos que implicam em obstáculos a serem enfrentados por alunos e docentes diante desse cenário. Obstáculos que devem ser superados a partir do entendimento de que, segundo Leão e colaboradores (2013), mesmo que as dificuldades se façam presentes, o emprego de recursos tecnológicos em um processo pedagógico representa uma alternativa essencial para que novas construções de conhecimentos sejam oportunizadas.

Acerca do design dos ambientes virtuais, Mozzaquatro e Medina (2008) apontam que ele deve ser amigável, atrativo e intuitivo, com o objetivo de facilitar o seu acesso por parte dos alunos, diminuindo, portanto, possíveis dificuldades relacionadas à busca pelas informações disponibilizadas pelos docentes.

Acerca dessa questão, os dados apresentados no Gráfico indicam notória aceitação do design do AVA por parte dos alunos, quando 148 alunos (82,2\%) afirmaram ser boa ou muito boa a qualidade de apresentação do ambiente virtual utilizado.

Gráfico 6 - Avaliação da qualidade de apresentação (design) do AVA.
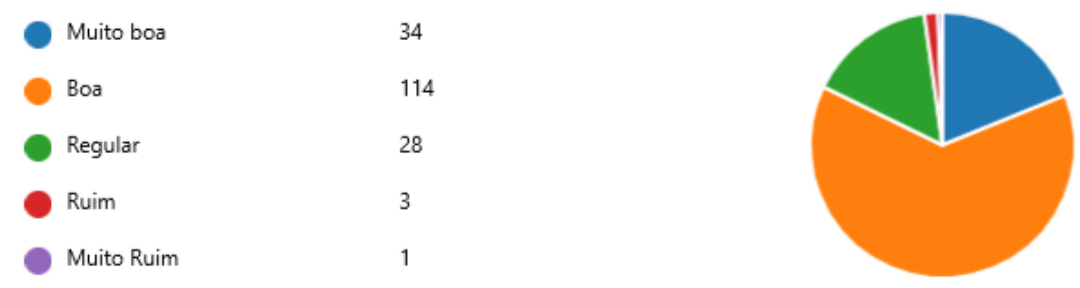

Fonte: Os autores

Outro aspecto avaliado se referiu aos componentes do AVA e, dentre eles, qual apresentou maior contribuição para a aprendizagem dos alunos. Sobre isso, verificou-se que os questionários representaram a principal ferramenta utilizada pelos sujeitos participantes do estudo, com 131 (72,7\%) menções, de acordo com os dados expostos no Gráfico 7. Observa-se que outros componentes foram citados pelos inquiridos, a saber, as aulas gravadas e os materiais disponibilizados pelos docentes. 
Gráfico 7 - Componente do AVA que apresentou maior contribuição para a aprendizagem

Fonte: Os autores

A respeito dessa questão, Avelino e colaboradores (2017) afirmam que um AVA deve conter variados componentes, permitindo, assim, o emprego de distintas mídias para a construção do conhecimento e assegurando adequações favoráveis a um aprendizado baseado nas múltiplas potencialidades e interesses dos alunos.

Não obstante, é possível perceber que esse interesse ainda se apresenta de maneira frágil, a considerar as opiniões dos alunos em relação ao processo de aprendizagem em AVA. Em consonância com o estudo de Wardenski e colaboradores (2018), mesmo que as TIC sejam constantemente utilizadas no cotidiano, grande parte dos jovens alunos ainda não a percebem como ferramenta de aprendizagem.

Sobre a opinião dos alunos participantes da pesquisa em relação às práticas pedagógicas empregadas pelos docentes nas atividades desenvolvidas no AVA, 124 inquiridos $(68,8 \%)$ se consideraram satisfeitos com as ações desenvolvidas. Entretanto, 47 alunos $(26,1 \%)$ qualificaram apenas como regular as práticas desenvolvidas, além de nove $(5 \%)$ que demostraram insatisfação em relação às elas.

Gráfico 8 - Avaliação das práticas pedagógicas utilizadas pelos docentes

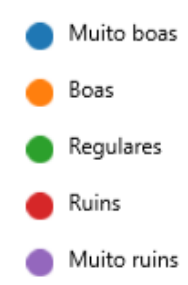

29
95
47
6
3

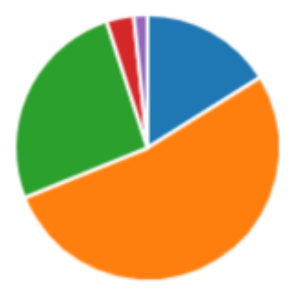

Fonte: Os autores

Para Wardenski e colaboradores (2018), tal nível de insatisfação pode estar associado ao fato de que é improvável a adesão dos alunos aos programas desenvolvidos no AVA, quando percebem uma frágil utilização ou até mesmo pouca adesão ao ensino desenvolvido através de TIC por parte dos docentes. Além disso, salienta-se que, em diversas ocasiões, os alunos estudam de acordo com as formas tradicionais de ensino e que, na maioria das vezes, tal 
procedimento não contempla as necessidades de um processo de aprendizagem desenvolvido no AVA.

Os métodos de avaliação utilizados no AVA pelos docentes também mereceram enfoque no presente estudo. A seu respeito, observou-se que 122 inquiridos $(67,7 \%)$ demonstraram-se satisfeitos com os procedimentos realizados (Gráfico 9).

Gráfico 9 - Opinião a respeito dos métodos de avaliação utilizados pelos docentes

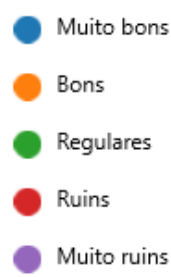
29
93
53
3
2

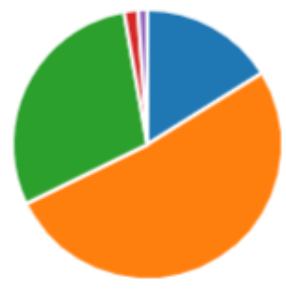

Fonte: Os autores

Segundo Laguardia e colaboradores (2007), um processo de avaliação pode ser considerado como a aplicação de procedimentos metodológicos com o intuito de determinar, diante de objetivos propostos pelos docentes e com base em critérios preestabelecidos, a relevância e o impacto de determinadas atividades com a finalidade de tomada de decisão. Os mesmos autores complementam com a afirmação de que uma avaliação em AVA pode estabelecer como referência as condições em que as ações pedagógicas foram realizadas, as maneiras pelas quais os alunos foram apoiados nessas mesmas ações e, por fim, o alcance dos objetivos/metas previamente propostos.

Nota-se ainda que, no AVA, torna-se possível a avaliação das estratégias de aprendizagem e as alterações ocorridas no rendimento dos alunos, o que acarreta evidências quanto aos processos pedagógicos realizados, sobretudo a eficácia das tecnologias educacionais (LAGUARDIA et al., 2007).

Sobre a opinião dos alunos quanto aos resultados obtidos nas tarefas avaliativas, constatou-se que 135 participantes (75\%) consideraram muito bons ou bons os resultados alcançados (Gráfico 10). 
Gráfico 10 - Avaliação dos resultados obtidos pelos alunos nas tarefas avaliativas

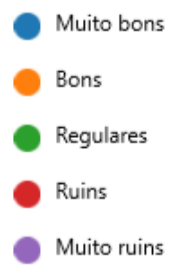

32
103
37
7
1

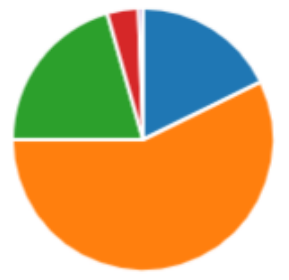

Fonte: Os autores

Faz-se necessária a observação de que a avaliação não deve ser compreendida unicamente como o ato de medir o aprendizado alcançado pelos alunos. Ela deve representar também um processo contínuo, que tem por finalidade a interpretação e o acompanhamento dos conhecimentos adquiridos pelos sujeitos, a considerar que, em uma ação educativa, almeja-se o alcance dos objetivos propostos para o programa em desenvolvimento (AGUIAR; CASSIANI, 2007).

\section{Considerações finais}

A partir dos resultados obtidos por intermédio do presente estudo, percebeu-se que a estrutura do AVA e o seu emprego para a realização das práticas pedagógicas foram bem aceitas pelos discentes participantes da pesquisa. Foi possível observar que o desenvolvimento das atividades acadêmicas nesse ambiente vem alcançando êxito quanto ao processo de aprendizagem dos estudantes, consolidando assim, além do ensino presencial, mais um cenário de aprendizagem para a educação física.

Além dos aspectos vinculados à estrutura do ambiente, acesso por parte dos discentes, práticas pedagógicas utilizadas pelos discentes e resultados alcançados, a aplicação do instrumento de coleta de dados permitiu a melhor compreensão acerca das dificuldades e necessidades por parte dos alunos, fato que remete a todos os envolvidos - docentes, instituição e os próprios alunos à reflexão e à discussão a respeito das melhorias necessárias, para que todas as potencialidades do AVA possam ser exploradas em prol de um processo que contribua de forma substancial para a formação acadêmica e profissional daqueles que o utilizam.

A realidade que é conhecida como "novo normal" proporcionou aos educadores o desafio de utilizar ferramentas tecnológicas, no sentido de 
favorecer as invocações do ensino e de oportunizar espaços cada vez mais apropriados para o desenvolvimento da aprendizagem. Uma aprendizagem que se ampara no intuito de assegurar aos alunos uma formação baseada em uma aprendizagem plural, além de fortalecer, diante de toda comunidade acadêmica, a percepção de que é inevitável a incorporação das TIC nas ações pedagógicas.

Almeja-se que esta pesquisa venha a contribuir para que o AVA venha a ser cada vez mais discutido pela comunidade acadêmica como um contributo, para que, diante desse que é considerado o "novo normal", as necessidades acadêmicas de alunos e instituições educacionais venham a ser contempladas em sua integralidade.

\section{Referências bibliográficas}

AGUIAR, R. V.; CASSIANI, S. H. B. Desenvolvimento e avaliação de ambiente virtual de aprendizagem em curso profissionalizante de enfermagem. Revista Latino-Americana de Enfermagem, São Paulo, n. 15, v. 6, [s.p.], nov./dez. 2007.

ANJOS, R. A. V. et al. Avaliação de Ambientes Virtuais de Aprendizagem: análise de alguns instrumentos e modelos constituídos. Informática na Educação: Teoria e Prática, Porto Alegre, v.19, n.2, p. 93-105, jun./set. 2016.

AVELINO, C. C. V. et al. Avaliação de ensino-aprendizagem no Cipe usando o ambiente de aprendizagem virtual. Revista Brasileira de Enfermagem, Brasília, v. 70, n. 3, p. 602-609, mai./jun. 2017.

BEHAR, P. A.; LEITE, S. M. The virtual learning environment Rooda: an institutional project of long-distance education. Journal of science education and technology, Gainsville, v. 15, n. 2, p. 159-167, 2006.

BOLÍVAR, C. R. La actitud del docente universitario hacia el uso educativo de las TIC: conceptualización y medición. Paradigma, Maracay, Venezuela, v. 33, n. 2, p. 7-25, 2012.

CORREIA, R. L.; SANTOS J. G. A importância da Tecnologia da Informação e Comunicação (TIC) na Educação a Distância (EAD) do Ensino Superior (IES). Revista Aprendizagem em EAD, Taguatinga, ano 2013, v. 2, p. 1-16, 2013.

LAGUARDIA, J. et al. Avaliação em ambientes virtuais de aprendizagem. Educação e Pesquisa, São Paulo, v.33, n.3, p. 513-530, set./dez. 2007.

LEÃO, M. F. et al. O uso de um ambiente virtual de aprendizagem como ferramenta de apoio ao ensino presencial. Abakós, Belo Horizonte, v. 2, n. 1, p. 32-51, nov. 2013. 
MOZZAQUATRO, P. M.; MEDINA, R. D. Avaliação do Ambiente Virtual de Aprendizagem Moodle sob diferentes visões: aspectos a considerar. CINTEDUFRGS Novas Tecnologias na Educação, Porto Alegre, v. 6 n. 2, [s.p.], dez. 2008

PINO, I. R. As TIC na formação a distância: reflexões contemporâneas. Revista Retratos da Escola, Brasília, v. 2, n. 2-3, p. 109-120, jan./dez. 2008.

PRADO C. et al. Teoria da aprendizagem significativa: elaboração e avaliação de aula virtual na plataforma Moodle. Revista Brasileira de Enfermagem, Brasília, v. 64, n. 6, p. 1114-1121, nov./dez. 2011.

RAMOS, S. R. Tecnologias da Informação e Comunicação: conceitos básicos (2008). Disponível em: http://esms.edu.pt/. Acesso em: 22 julho 2020.

REPETTO, G. T. et al. Nuevas tecnologías en educación superior. Estudio de percepción en estudiantes acerca del uso de WhatsApp y Entornos Virtuales de Aprendizaje (Plataforma Moodle). Odontoestomatología, Montevidéo, v. 20, n. 33, p. 37-43, jan.jun. 2019.

SALVADOR, P. T. C. O. et al. Objeto e ambiente virtual de aprendizagem: análise de conceito. Revista Brasileira de Enfermagem, Brasília, n. 70, v. 3, p. 599606, mai./jun. 2017.

SANTOS, A. C. Z. F. et al. Avaliação e desenvolvimento de ambiente virtual de aprendizagem no ensino da disciplina de Diagnóstico Oral por meio do blended learning. Revista da ABENO, São Paulo, v. 17, n. 2, p. 76-87, 2017.

WARDENSKI, R. F et al. Continuidade e descontinuidade de uso de tecnologias digitais de informação e comunicação por professores universitários das ciências e da saúde. Ciênc. Educ., Bauru, v. 24, n. 3, p. 621-638, 2018. 